\title{
FRAGMENTOS DE CÓDICES LITÚRGICO-MUSICALES EN ESPAÑA: APUNTES PARA UNA HISTORIOGRAFÍA Y UNA PROPUESTA DE DESCRIPCIÓN
}

\author{
POR \\ DAVID ANDRÉS FERNÁNDEZ ${ }^{1}$ \\ Universidad Austral de Chile \\ Y \\ CRISTINA MARTí MARTÍNEZ ${ }^{2}$ \\ Universidad Internacional de La Rioja
}

\begin{abstract}
RESUMEN
Desde la Edad Media, diversas circunstancias han fomentado la destrucción de los códices litúrgicos y la reutilización de sus folios. Los fragmentos subsistentes son prueba de lo que otrora formó parte de la cultura escrita en Occidente, por lo que estas fuentes primarias permiten conocer diversos aspectos de nuestra historia. En España, algunos investigadores han identificado y estudiado estos restos documentales, particularmente los litúrgico-musicales. Este artículo realiza una revisión historiográfica de las investigaciones efectuadas en España en la materia y propone, en base a esa revisión, una ficha descriptiva que pueda utilizarse como modelo en el análisis de dichos fragmentos que sirva a su vez de diseño de los campos en una potencial base de datos o catálogo colectivo en español. Como resultado, se ha actualizado la información en la materia y dispuesto una ficha descriptiva exhaustiva, rigurosa y adaptada a los estándares más aceptados.
\end{abstract}

PALABRAS CLAVE: fragmento; liturgia; canto llano; codicología; musicología; archivística; bases de datos; Edad Media.

\section{FRAGMENTS OF MUSICAL-LITURGICAL CODICES IN SPAIN: NOTES FOR AND HISTORIOGRAPHY AND A PROPOSAL OF DESCRIPTION}

\begin{abstract}
From the Middle Ages, several circumstances have caused the destruction of liturgical manuscripts with music and their reutilisation. The remaining fragments are proof of what once was part of the Western written culture, therefore these primary sources provide insight into diverse aspects of our history. In Spain, some researchers have identified and studied those fragments, particulary the musico-liturgical ones. This article shows a historiographic review on the field, and propose, based on this review, a form for description which can be used as a model in their analysis, and serve as well as fields in a potential database in Spanish language. As a result, the information on the topic has been updated, and an accurate, and detailed descriptive-template has been addressed to the more accepted standards.
\end{abstract}

KEY WORDS: fragment; liturgy; plain-chant; codicology; musicology; library science; databases; Middle Ages.

Cómo CITAR este artículo / Citation: Andrés Fernández, D. y Martí Martínez, C. 2017. «Fragmentos de códices litúrgico-musicales en España: apuntes para una historiografía y una propuesta de descripción». Hispania Sacra 69, 139: 49-60 doi: 10.3989/ hs.2017.004

Recibido/Received 31-03-2016

Aceptado/Accepted 24-04-2016

\footnotetext{
dandres@uach.cl / ORCID iD: http://orcid.org/0000-0002-2842-226X

cristina.marti@unir.net / cmartimartinez@gmail.com / ORCID iD: http://orcid.org/0000-0002-5157-3963
} 


\section{INTRODUCCIÓN}

Los fragmentos y membra disiecta como parte de ellos son fuentes que forman parte del acervo cultural de nuestra sociedad. ${ }^{3}$ Así, su estudio constituye una línea de investigación que cuenta con una considerable tradición historiográfica, tanto en el extranjero como en el territorio nacional español. ${ }^{4}$

Concretamente, dentro de los fragmentos, los litúrgicos conforman un amplio e importante corpus..$^{5}$ Efectivamente, estos documentos especiales aportan datos relevantes para la comprensión de aspectos culturales de la historia, así como abundante información litúrgica y religiosa al ser, a su vez, testigos de la fe de unas comunidades cristianas determinadas. No es por tanto de extrañar que encontremos diversas citas acerca de la relevancia de los trabajos de recuperación, descripción y salvaguarda de fragmentos de este tipo, así como de su utilidad, ni tampoco lo es que diversos hispanistas hayan mostrado las razones para investigarlos y apuntado además hacia la creación de un catálogo colectivo con el objetivo de obtener resultados heurísticos más profundos. Por ejemplo, T. Burón, quien dedicó una parte considerable de su obra al estudio de fragmentos litúrgicos, sugirió a archiveros y bibliotecarios "una recuperación sistemática» de los mismos para admirar y conocer mejor el pasado. ${ }^{6}$ En el caso de los litúrgico-musicales, $\mathrm{H}$. Anglés ya se había referido a ellos en 1935 como documentos útiles en el análisis de la música medieval en la región catalana, ${ }^{7}$ señalando la falta, para ese territorio, de un catálogo conjunto de fuentes que permitiera obtener unas conclusiones más complejas. ${ }^{8}$

Estas mismas preocupaciones fueron compartidas a nivel nacional setenta años más tarde, en 2005, en la XXI Asamblea de la Asociación de Archiveros de la Iglesia en España, en donde se propuso "Apoyar el estudio de los fragmentos de pergaminos musicales existentes en archivos eclesiásticos y animar a la creación de inventarios, así como crear un corpus colectivo que los recoja». ${ }^{9}$ Sin embargo, aunque no cabe duda de que la investigación en este tema ha seguido vigente, y de que, por tanto, se ha continuado con la tarea de recopilación, análisis y descripción de estas fuentes en archivos del estado español, tanto eclesiásticos como civiles, hoy día sigue sin existir, como tampoco existe en España un catálogo colectivo de fragmentos o códices, y mucho menos de los litúrgicos, musicales o no. Mientras que en el extranjero se han multiplicado los catálogos conjuntos sobre fuentes musicales en general, y de música litúrgica en particular (principalmente en forma de base de datos online), ${ }^{10}$ en

3 Para conocer los diversos términos aplicables a los fragmentos, véase Díaz y Díaz 1992: 39 y 43, y Muzerelle 1985.

4 Véanse como ejemplo para el extranjero Pellegrin 1980; Perani y Ruini (eds.) 2002 y Fassler 2010.

5 Cf. Baroffio 1995-1996.

6 Burón Castro 1987: 389. El autor incluso llegó a publicar un manual en la materia: Burón Castro 2002.

7 Anglés 1935: xii-xiii.

8 Cf. Ibídem: 133

9 Hevia Ballina (ed.) 2008: 806, conclusión no 8 .

10 A modo de ejemplo mencionaremos aquí las principales y más estables: CANTUS Index: Online catalogue for Mass and Office chants, http://cantusindex.org/ [consultado: 10/01/2016, que comprende a su vez Cantus Database, Portuguese Early Music Database, Slovakian Early Music Database, Gradualia Project, Fontes Cantus Bohemiae y Cantus Planus in Polonia, así como Cantus Planus Regensburg's
España ninguna institución, pública o privada, ha fomentado la producción de un corpus colectivo que pueda favorecer a los investigadores de diversas disciplinas (paleógrafos, liturgistas, musicólogos, filólogos, etc.) la accesibilidad a toda la información que proveen estos documentos, los cuales, dicho sea de paso, se hallan ampliamente diseminados.

Sin duda, al margen de la situación actual de estos fragmentos y de las razones que motivaron su desuso, ${ }^{11}$ la creación de un catálogo colectivo o base de datos conjunta de fragmentos litúrgicos permitiría conocer aspectos que de otro modo pasarían inadvertidos o serían imposibles de discernir. Así, una herramienta semejante posibilitaría el restablecimiento de códices litúrgicos cuyos fragmentos se hallan dispersos en diferentes lugares geográficos. En efecto, el cotejo de los contenidos de diversos fragmentos hallados en un mismo archivo o en archivos diferentes permitiría establecer similitudes que ayuden a componer, en la medida de lo posible, códices completos, así como a proponer pautas de difusión y recepción de modelos y arquetipos. ${ }^{12}$ Como ejemplo, M. Díaz y Díaz ha demostrado que en una región como Galicia, en la que no sobrevivió apenas ningún códice íntegro, el descubrimiento de fragmentos dio una idea de los libros de la zona y permitió saber, al menos para este territorio y el Norte de Portugal, que se siguieron empleando técnicas paleográficas y codicológicas en boga en siglos anteriores hasta mucho más allá de $1100 .{ }^{13}$ Como consecuencia de lo anterior, los fragmentos reagrupados según su pertenencia a un códice original permitirían a su vez la reconstrucción de scriptoria y bibliotecas monásticas, eclesiásticas o parroquiales, medievales o modernas, tal y como ya fue indicado por C. Rodríguez Suso y T. Burón. ${ }^{14}$

Por otra parte, un catálogo conjunto ayudaría a comprender mejor las transformaciones vinculadas a la producción y cultura escrita, como por ejemplo el proceso de abandono y cambio de ciertas notaciones musicales en la Edad Media. De ese modo se actualizarían los conocimientos que tenemos acerca de la notación musical de ese período, complementando los trabajos de S. Zapke y C. Rodríguez Suso para las transiciones de las notaciones musicales en el medioevo

Regensburg's data pool for research in Gregorian Chant, http://www. uni-regensburg.de/Fakultaeten/phil_Fak_I/Musikwissenschaft/cantus/index.htm [consultado: 10/01/2016], Global Chant: database of melodies and texts of Gregorian Chant, http://www.globalchant.org [consultado: 16/01/2016], The CAO-ECE Project, http://earlymusic. zti.hu/ [consultado: 16/01/2016] y DIAMM-Digital Image Archive of Medieval Music, http://www.diamm.ac.uk [consulta: 13/03/2015], las cuales están destinadas principalmente para el uso comparativo de repertorios litúrgico-musicales, incluyendo descripciones bastante completas de los códices que catalogan, si bien el número de fragmentos que contienen es bastante menor si lo comparamos con aquel de los manuscritos completos. Otras de interés para este trabajo son: Celebrating the Liturgy's Books: Medieval \& Renaissance MS in NYC, http://www.columbia.edu/itc/music/manuscripts/index.html [consultado: 10/01/2016], que incluye una interesante colección de la Hispanic Society con manuscritos procedentes de España, así como los específicos de fragmentos en Dinamarca (Liturgical fragments from Denmark, Database on Danish Liturgical Fragments from the Middle Ages, http://www.liturgy.dk [consultado: 10/01/2016]) y en Suecia (Brunius 2002, con más de veintitrés mil fragmentos).

11 Sobre estas cuestiones puede consultarse Conde López 1997.

12 Prensa Villegas 2004: 17.

13 Díaz y Díaz 1992: 43.

14 Rodríguez Suso 1993b: 705 y Burón Castro 1995b: 507. 
hispano; de visigótica a aquitana y de aquitana a cuadrada respectivamente. ${ }^{15}$ De forma similar, con ayuda de la paleografía, sería posible estimar con mayor rigor dataciones tópicas y crónicas de fragmentos dispersos y, por tanto, de los códices a los que pertenecieron, posibilitando también conocer el origen y fecha de otros fragmentos de similares características paleográficas y/o codicológicas. ${ }^{16}$

Asimismo, esta propuesta permitiría ampliar la información de algunas de las preocupaciones investigadoras que han sido tratadas previamente en otras disciplinas. De este modo, la comparación de fragmentos permitiría comprender mejor el culto litúrgico de determinados centros del mapa eclesiástico de una zona o región determinada, al ser los fragmentos litúrgicos elementos privilegiados en la reconstrucción de modelos de celebración específica de distintas diócesis y centros monásticos. ${ }^{17}$ Pero también sería útil en el estudio de la decoración e iluminación como parte de la historia del arte, aportando datos que favorezcan la identificación de escuelas o estilos ibéricos involucrados en la producción escrita, permitiendo además, por comparación, la observación de diferencias, similitudes e influencias entre los diversos centros productores o scriptoria. ${ }^{18}$ También, en el ámbito filológico, podría proporcionar un corpus de textos o testimonios, inéditos o no, que ayudaran a la mejor comprensión de un acontecimiento puntual y a la difusión de una obra determinada a través de las transformaciones que sufrió en su transmisión. ${ }^{19}$

Por estas razones, este artículo, que desarrolla un trabajo anterior inédito, ${ }^{20}$ presenta una síntesis historiográfica sobre el estudio de los fragmentos litúrgico-musicales en España, y, establece, en base a ésta, los parámetros de una ficha de descripción de fragmentos que pueda servir como punto de partida en la creación de una potencial base de datos o catálogo colectivo que aglutine la información de los vestigios de códices litúrgico-musicales disponibles hoy en este país. La concepción de esta herramienta se plantea de forma transversal, ya que su existencia favorecería, como hemos advertido, a varias disciplinas, si bien está diseñada principalmente para fuentes de canto llano o, si se prefiere, monódicas. Además, los parámetros descriptivos, que han sido pensados para ser utilizados en idioma español, serán probados mediante su implementación a un fragmento inédito del Archivo Histórico Provincial de Zaragoza. ${ }^{21}$

\section{SÍNTESIS HISTORIOGRÁFICA SOBRE LOS FRAGMENTOS LITÚRGICO-MUSICALES}

Aunque podríamos aducir alusiones anteriores, es significativo que, a mediados del siglo XIX, Dom A. Dold, bajo la máxima bíblica «colligite quae superaverunt fragmenta, ne

\footnotetext{
15 Zapke 2007c y Rodríguez Suso 1993b.

16 Cf. Mundó 1982.

17 Cf. Zapke 2007a: 8.

18 Zapke (ed.) 2007b: 26.

19 Alturo Perucho 1990: 51.
}

20 Martí Martínez 2013. Sirva esta nota para agradecer a Arturo Tello la dirección de dicho trabajo, así como la revisión de la primera versión de este texto.

21 Otros fragmentos de este archivo fueron previamente publicados en Andrés Fernández 2013. pereant», ${ }^{22}$ hiciera suya la locución «colligere fragmenta, ne pereant» para prestar atención a la búsqueda y estudio de fragmentos litúrgico-musicales. ${ }^{23}$ Este interés por los fragmentos coincidió con el movimiento reformista del canto monódico litúrgico que tuvo lugar en varios países europeos y que fue impulsado en gran medida por el monje solesmense Dom P. Guéranguer. ${ }^{24}$ Como consecuencia, el interés por descubrir e investigar códices medievales aumentó paulatinamente, si bien no fue hasta la década de 1950 cuando empezaron a proliferar catálogos acerca de la música litúrgica contenida en archivos y bibliotecas. ${ }^{25}$

Fue entonces cuando los investigadores comenzaron a recuperar también los fragmentos litúrgico-musicales de forma sistemática. ${ }^{26}$ Podríamos, por tanto, considerar como uno de los trabajos pioneros el realizado por L. Brou en 1950 sobre los fragmentos visigóticos guardados en la universidad cantabrigense. ${ }^{27}$ En este sentido, encontramos que los especialistas tardaron, al menos, quince años más en prestar atención a los fragmentos de la liturgia hispánica o hispano-visigótica guardados en España, ${ }^{28}$ destacando en número las contribuciones que T. Burón realizó durante más de una década para los archivos leoneses. ${ }^{29}$ No obstante, aproximadamente en los mismos años J. Janini hacía lo propio con otros fragmentos y códices litúrgicos, musicales o no, en diversos depósitos documentales del país. ${ }^{30}$

Posteriormente, fue a finales de los años ochenta y principios de los noventa cuando se renovó el interés por los fragmentos litúrgicos, especialmente por aquellos con notación musical. Este interés ha continuado hasta nuestros días y tenido lugar principalmente a dos niveles: regional -por comunidades autónomas- y local -en catálogos de archivos concretos-, con alguna excepción de carácter nacional. No obstante, podríamos clasificar los proyectos de recuperación, descripción y/o estudio de los fragmentos con música de la siguiente forma:

a) Como proyecto individual:

- De forma monográfica para una comunidad autónoma o región concreta: $C$. Rodríguez Suso en el País Vasco, ${ }^{31}$ M. C. Peñas en Navarra, ${ }^{32}$ P. Extremiana

22 Juan 6,12: «Recoged los trozos sobrantes para que nada se pierda».

23 Alturo Perucho 1990: 52.

24 Sobre la reforma en general véanse Bergeron 1998 y más recientemente Ellis 2013. Para España véase Fernández de la Cuesta 1991.

25 Algunas ideas que justifican el estudio de la historia de la liturgia y de sus fuentes en esta reforma pueden encontrarse en Guéranger 1840-1841: I, 6-16. Otro ejemplo, en este caso musical, lo constituyen las posibles concordancias de fuentes de diverso origen geográfico para determinar la pureza de una melodía: Cf. Ibídem: 306, traducido al español en Asensio Palacios 2003: 129.

26 Cf. Zapke 2007a: 8.

27 Brou 1950.

28 Janini Cuesta 1966 y 1968; Varona García 1973; Gros Pujol 1977 y Fernández de la Cuesta y Del Álamo 1979.

29 Burón Castro 1973, 1978, 1979, 1980, 1981 y 1985.

30 Sobre los códices daremos algunas referencias más adelante, por lo que anotaremos en esta nota sólo la bibliografía referente a los fragmentos: Janini Cuesta 1965, 1975, 1976a y 1976b; Janini Cuesta y Ricoma 1965.

31 Rodríguez Suso 1993a y 1993 b.

32 Peñas García 2004. 
en La Rioja, ${ }^{33}$ R. M. Conde en Cantabria ${ }^{34}$ y M. Rey Olleros en Galicia. ${ }^{35}$

- De un repertorio específico: S. Zapke para los fragmentos, como parte de los manuscritos, hispanos de los siglos IX al XII. ${ }^{36}$

- En forma de estudio para determinados archivos: A. Medina para el Ayuntamiento de Oviedo, ${ }^{37}$ T. Burón en archivos leoneses, ${ }^{38}$ E. Núñez Fernández en el Archivo Municipal de Gijón ${ }^{39}$ y S. Ruiz Torres en el Archivo de la Catedral de Huesca. ${ }^{40}$

b) Como trabajo colectivo o de varios autores:

- Colectivo: el editado por P. Calahorra para el Archivo Histórico Notarial de Daroca en Aragón, ${ }^{41}$ resultado del equipo de la Cátedra de Música Medieval Aragonesa de la Institución Fernando el Católico para el estudio de fuentes litúrgico-musicales en Aragón. ${ }^{42}$ Entre los trabajos de dicha cátedra podríamos además considerar el de $\mathrm{M}$. T. Ibarz sobre fragmentos de protocolos notariales en dicha región, ${ }^{43}$ el de D. Andrés para el Archivo Histórico Provincial de Zaragoza ${ }^{44} \mathrm{y}$, en cierto modo, el de S. Zapke para algunos archivos oscenses. ${ }^{45}$

- De varios autores: C. J. Gutiérrez y F. Lara para el Archivo Diocesano de Astorga, ${ }^{46}$ C. Castillo y A. Romero para el Archivo Histórico Eclesiástico de Vizcaya,${ }^{47}$ y A. Sánchez y J. A. Pelayo para un fragmento del Archivo Municipal de Loja, Granada. ${ }^{48}$

Como hemos advertido, existen además otras obras que catalogan fuentes litúrgico-musicales a nivel nacional, como la aportación de J. Garrigosa para manuscritos e impresos de archivos de gestión estatal, que incluye algunos fragmentos, ${ }^{49}$ así como la selección de manuscritos y fragmentos que publicó I. Fernández de la Cuesta en $1980 .{ }^{50}$ Asimismo, otros autores han utilizado fragmentos individuales o conjuntos de ellos como herramienta en sus investigaciones, como por ejemplo M. Martín, ${ }^{51}$ M. Gros ${ }^{52}$ y S. Ruiz ${ }^{53}$ para temas litúrgi-

33 Extremiana Navarro 2002 y Extremiana Navarro y Camacho Sánchez 2004.

34 Conde López 1998.

35 Rey Olleros 2007-2009; Rey Olleros 2013a, 2013b y 2013c.

36 Zapke 2007b.

37 Medina Álvarez 1994.

38 Las referencias arriba citadas, así como Burón Castro 1992, 1997 y 2000.

39 Nuñez Fernández 1995.

40 Ruiz Torres 2016.

41 Calahorra Martínez 2011, cuyo primer informe provisional puede consultarse en Prensa Villegas 2010.

42 Algunos de los avances del Programa Fragmentos de la Cátedra de Música Medieval Aragonesa pueden consultarse en Ídem, así como en Prensa Villegas 2000 y Calahorra Martínez 2004.

43 Ibarz Ferré 1998, cuyo informe preliminar fue publicado en Ibarz Ferré 1997.

44 Andrés Fernández 2013.

45 Zapke 2007a.

46 Gutiérrez González y Lara Lara 1992.

47 Castillo Pérez y Romero Andonegi 2008.

48 Sánchez Mairena y Pelayo Piqueras 2015.

49 Garrigosa Massana 1994.

50 Fernández de la Cuesta 1980.

51 Martín Fuertes 1987.

52 Gros Pujol 1977, 1995, 1998, 2008, 2009 у 2013.

53 Ruiz Torres 2010. cos, y los publicados por M. Gómez Muntané, ${ }^{54} \mathrm{~K}$. Nelson ${ }^{55} \mathrm{O}$ B. Cabero ${ }^{56}$ para el estudio de la música polifónica en la baja Edad Media y principios de la Moderna.

Por otro lado, los resultados de nuestra síntesis se multiplicarían al considerar también aquéllos sobre monasterios, catedrales y otros archivos de colegiatas, iglesias, conventos, etc., presentes o pretéritos. Efectivamente, la magnitud de trabajos dedicados a la catalogación, identificación y estudio de manuscritos litúrgicos que pudieran contener fragmentos con música es enorme. ${ }^{57}$ De este modo, es posible encontrar fragmentos litúrgico-musicales en los catálogos de J. Janini en diversos archivos del territorio español, 58 así como los de J. Janini ${ }^{59}$ y J. Alturo en Cataluña. ${ }^{60}$ Por esta razón, hemos mostrado aquí aquellos que consideramos más relevantes y los que hemos estimado útiles en la elaboración de nuestra propuesta de ficha descriptiva.

\section{FICHA DESCRIPTIVA: ANTECEDENTES Y PROPUESTA}

Una atenta observación a las publicaciones citadas muestra las dificultades encontradas en el estudio de los fragmentos litúrgicos en general, sobre todo en lo que respecta a los datos que contienen las fichas catalográficas que los describen. Al margen de las evidentes diferencias en extensión, cantidad de información y nivel de detalle, hemos detectado que, efectivamente, las metodologías utilizadas presentan disimilitudes en cuanto a los criterios utilizados en sus análisis: a pesar de que las reglas y normas de catalogación de manuscritos comenzaron a sistematizarse en España desde mediados la década de 1970 hasta principios de la de 1990, ${ }^{61}$ en general, los estudiosos no han seguido de forma consistente dichas normas para describirlos, lo que ha producido una heterogeneidad entre los resultados de las publicaciones disponibles, como se observa al comparar trabajos de diversos autores.

Una de estas divergencias, quizás la más significativa para este trabajo, es la disparidad tanto en la elección de los campos descriptivos como en la terminología empleada para describir dichos campos. Esto puede ser fruto o bien de que, a priori, no se acuerde una propuesta terminológica inicial, o bien por una falta de formación especializada en liturgia y/o musicología, hecho que ha sucedido en ocasiones en el personal de los archivos de la administración pública. Los ejemplos más evidentes son: 1) la desigualdad de criterios en la elección de la nomenclatura de tipología libraria (e.g.: Antifonario del Oficio, Antiphonarium o Antiphonale officii), 2) el uso indistinto, incluso en un mismo texto, de diversos términos o lenguas para referirse a un mismo concepto (custos y custus, línea tendida y línea tirada, etc.), y 3) la ausencia de especificaciones técnicas u omisión de ciertos

\footnotetext{
54 Gómez Muntané 1985 y 1989-1990.

55 Nelson 1993.

56 Cabero Pueyo 1992.

57 Un amplio listado de esas fuentes puede consultarse en Sánchez Mairena 2015: fragmentos en 670-675.

58 Janini Cuesta 1977 y 1980.

59 Janini Cuesta 1978.

60 Alturo Perucho 1999.

61 Bohigas, Mundó y Soberanas 1973-1974; Ruiz García 1988 y Baroffio 1990.
} 
datos (e.g.: falta de la forma del pautado del fragmento; a punta seca, a tinta, o similares).

Muy relacionado con lo anterior es la complejidad terminológica asociada a la nomenclatura paleográfica empleada, sobre todo en lo que concierne al tipo de letra más que a la notación musical. A pesar de la aparente uniformidad de las escrituras presentadas en este tipo de códices (y, por tanto, de sus fragmentos), parece no haber todavía consenso sobre la clasificación de los tipos de letras. Sirva de ejemplo el caso de la escritura gótica libraria, cuya terminología sigue en discusión en Europa desde mitad del siglo $x^{62}$ hasta la actualidad, ${ }^{63}$ encontrando distintas propuestas de nomenclatura en el ámbito hispano según el autor que corresponda. ${ }^{64}$ Este hecho no es de extrañar dado que desde, al menos, el siglo XVI tenemos constancia de que los autores utilizaban los mismos términos para describir diferentes tipos de letra y viceversa, es decir, diferentes términos para un mismo tipo de letra. ${ }^{65}$

A esto habría que añadir la falta de unidad en el etiquetado y categorización para este tipo de fragmentos, hecho que dificulta su búsqueda y localización, sobre todo en catálogos digitales. Así, hemos encontrado los siguientes casos en el Portal de Archivos Españoles (PARES): ${ }^{66}$ dentro del fondo de Real Audiencia y Chancillería de Valladolid del Archivo de la Real Chancillería de Valladolid aparecen expresiones como "trozos de pergamino», "música gregoriana», "fragmentos», «hoja de cantoral sacro vocal», «hoja incompleta de texto y música con pentagramas» «, «hoja doble de un libro eclesiástico escrito a doble columna, texto y música» y otras similares para referirse al tipo de documento que aquí tratamos. Pero incluso puede darse el caso de que el catálogo de un depósito particular no señale la aparición de música en un fragmento que sí la tiene, hecho que resulta significativo en una institución como la Biblioteca Nacional de España (BNE); nos referimos al fragmento que acompaña al documento RES/203 de este depósito, cuya descripción no hace alusión alguna a la significativa cantidad de música en notación aquitana que contiene. ${ }^{67}$

Otro factor que también hace presentar resultados disímiles en la descripción de fragmentos es la transcripción del contenido, que puede variar desde una transcripción fiel a la ortografía original, como en Hispania Vetus de S. Zapke, ${ }^{68}$ útil para el filólogo, hasta una uniformizada a las modernas convenciones latinas, criterio adoptado, por ejemplo, por Cantus Index ${ }^{69}$ para facilitar la localización de una misma pieza en fuentes diversas. En este caso, los autores adoptan una opción a favor del objetivo principal del trabajo, si bien

\footnotetext{
62 Lieftinck 1953.

63 Derolez 2003.

${ }^{64}$ Por ejemplo, compárese la terminología de Canellas López 1974 frente a Álvarez Márquez 1985.

${ }^{65}$ Berenbeim 2010.

66 PARES-Portal de Archivos Españoles, http://pares.mcu.es/ [consultado: 10/01/2016].

67 «Una h. de guarda al principio, formada por tres fragmentos de códices en perg. que contiene una poesía atribuida al mismo autor, que empieza: "Dret de natura comanda / don amors pren naissement" ". Accesible en http://bdh.bne.es/bnesearch/detalle/2694699 [consultado: 10/01/2016].

${ }_{68}$ Zapke 2007b.

${ }^{69}$ Lacoste et ar. 2012.
}

la principal crítica aquí es la omisión generalizada de los criterios por los que se toma dicha decisión.

De modo similar, hemos encontrado otras diferencias y problemas en los textos revisados. Por ejemplo, se aprecia que, cuando corresponde, no se trata de la misma forma al documento asociado al fragmento. Así, no todos aportan información de dónde se encontraban los fragmentos, otros los analizan ya extraídos de los libros o de los legajos, una vez limpios y restaurados, y también los hay que no dan importancia a los datos del archivo (fechas, tipo de legajo, años de la encuadernación, etc.). Además, el avance de la paleografía, la codicología, la archivística y la biblioteconomía como disciplinas (ahora denominadas Ciencias y Técnicas Historiográficas y Ciencias de la Documentación e Información respectivamente), así como las recientes revisiones y reordenaciones de los fondos de los archivos españoles que tienden hacia la estandarización de campos con normas internacionales, muestran que los mismos fondos pueden ser catalogados de diversas formas. Sirva de ejemplo, aunque no específico para fragmentos, las alusiones al repertorio litúrgico-musical de los catálogos del Archivo de Música de la Catedral de Salamanca: el realizado por D. García Fraile en $1981,{ }^{70}$ y el coordinado por J. Montero García, publicado en $2011 .^{71}$

Atendiendo, por tanto, a todos los precedentes expuestos, nuestro objetivo no es otro que proponer un modelo de ficha descriptiva de fragmentos litúrgico-musicales que evite los problemas aquí descritos. Para ello, hemos tomado como punto de partida los criterios establecidos en los trabajos sobre fragmentos de P. Calahorra y C. Rodríguez Suso. ${ }^{72}$ Esto ha supuesto ciertas ventajas y mejoras en relación a otros modelos, puesto que al seguir a estos autores disponemos, de partida, de una ficha descriptiva completa que incluye información acerca del propio fragmento, de los datos archivísticos escritos en los pergaminos y de su digitalización (en su caso), así como de la posible procedencia del códice, del momento aproximado de la reutilización y de otros detalles afines y de interés para el investigador. Pero también hemos considerado en nuestra propuesta pautas generales de otras guías internacionales, como las de $A$. Hughes, ${ }^{73}$ B. Baroffio, ${ }^{74}$ M. Tedeschi ${ }^{75}$ y Cantus Database, ${ }^{76}$ así como elementos puntuales de otras aportaciones nacionales que consideran numerosos criterios de descripción, como los de A. Medina, ${ }^{77}$ J. C. Asensio, ${ }^{78}$ y, en especial, el Catálogo Cantorales de la BNE. ${ }^{79}$

En este proceso, hemos evaluado cuál es la terminología más habitual, el tipo de información más relevante y la forma más aceptada de exponer los datos dentro del variado rango de textos disponibles. Esto supone un avance sustancial con respecto a modelos anteriores puesto que permite proponer una ficha que cumple los principios de

\footnotetext{
70 García Fraile 1981.

71 Montero García (ed.) 2011.

72 Calahorra Martínez 2011 y Rodríguez Suso 1993.

73 Hughes 1995.

74 Baroffio 1990.

75 Tedeschi 1990.

76 Cantus: a database for Latin Ecclesiastical Chant, http://cantus. uwaterloo.ca/ [consultado: 16/01/2016].

77 Medina Álvarez 1994.

78 Asensio Palacios 2003.

79 Catálogo Cantorales - BNE, http://www.bne.es/es/Catalogos/ Cantorales/ [consultado: 16/01/2016].
} 
estandarización básicos y que sigue también las principales directrices descriptivas que se han utilizado en el análisis de manuscritos y fragmentos. Además, por este motivo, en los casos dudosos que disponen de diversas opciones válidas, hemos anotado adicionalmente, en una nota a pie de página de la ficha, el autor o catálogo al que seguimos, junto con la razón que ha determinado dicha elección. De este modo, la propuesta de ficha descriptiva de fragmentos litúrgico-musicales en español considera todos y cada uno de los diferentes modelos vistos, así como las guías de descripción de manuscritos musicales mencionados, por lo que consideramos que su principal ventaja es la presentación de sus contenidos de forma homogénea en base a un estudio riguroso sobre los trabajos previos existentes, en previsión a validarse como plantilla de un potencial y futuro catálogo colectivo o base de datos. Veamos a continuación esta ficha.

\section{FICHA DESCRIPTIVA PROPUESTA}

Resumen del ítem: signatura, tipología libraria, ocasión litúrgica y datación. ${ }^{80}$

\section{A. Identificación}

- Siglas RISM/PARES del centro poseedor. Relacionar con una tabla que contenga:

- Nombre poseedor: (archivo / biblioteca). ${ }^{81}$

- Otros nombres por los que se le conoce.

- Dirección postal.

- Tipo de centro: (Civil / público / eclesiástico / colección particular).

- Diócesis (si procede).

- Persona de contacto archivo/biblioteca (no visible).

- Signatura completa o cota

B. Imagen ${ }^{82}$

- Signatura digital, en su caso.

- Enlace al objeto digital o a la URL externa.

- Derechos de acceso y reproducción.

C. Análisis externo

- Tipo documento: (selección: fragmento / membra disiecta).

- Tipo de libro: (selección: de listado). ${ }^{83}$

- Datos de la reutilización

- Datación de la reutilización: (selección: desconocida / aproximada / cierta. Dato).

- Reutilización: (selección: cubiertas / revestimiento / refuerzo / decoración). ${ }^{84}$

- Datos de procedencia o antiguos poseedores.

- Anotaciones de archivo: (selección: SI / NO).

- Sellos.

- Otros fragmentos extraídos del mismo liber tradens.

80 Estos datos relevantes serán tomados automáticamente de la información registrada en los campos correspondientes de la ficha.

81 Rodríguez Suso 1993b lo denomina «procedencia inmediata».

82 Sería necesario planificar un sistema de almacenaje e identificación de las imágenes mediante la signatura y/o sigla.

${ }^{83}$ A pesar de que existen nomenclaturas y clasificaciones internacionales, como Huglo 1980 y Palazzo 1993 (trad. en Palazzo 1998), tomaremos aquí aquella propuesta por el proyecto Cantorales de la Biblioteca Nacional de España, el cual a su vez sigue a Fonseca Ruiz (ed.) 1999: Anexo II, 488-489.

84 Cf. Medina Álvarez 1995.
- Del fragmento.

- Dimensiones fragmento (altox ancho, en milímetros).

- Caja escritura:

$\square$ Tipo: (selección: dos columnas / línea tirada / otro).

$\square$ Dimensiones: alto $x$ ancho, en milímetros.

- Medidas intercolumnio (en su caso, en milímetros).

- Número de líneas.

- Foliación: (selección: SI / NO / foliación posterior). $\square$ Tipo de foliación: (Dato: romanos / arábigos / alfanumérico).

$\square$ Reclamos: (selección: SI / NO. Dato).

- Decoración. ${ }^{85}$

- Datación fragmento: (selección: desconocida / estimada / cierta. Dato).

- Estado de conservación

$\square$ Selección 1: (in situ -si aún se encuentra en la encuadernación- / restaurado / no restaurado).

$\square$ Selección 2: (bueno / regular / malo).

- Posibles copistas o amanuenses.

- Escritura

- Textual

$\square$ Tipología (selección: visigótica / carolina / gótica / otra. Dato). ${ }^{86}$

$\square$ Lengua. ${ }^{87}$

$\square$ Módulos empleados.

$\square$ Abreviaturas / Braquiografía.

$\square$ Colores.

- Musical (selección: con notación / sin notación)

$\checkmark$ Tipología (selección: viejo-hispánica / aquitana / cuadrada / otra. Dato).

$\square$ Líneas / pautas.

$\square$ Claves.

$\square$ Línea de trazo (selección: SI / NO).

$\square$ Custos (selección: SI / NO).

D. Análisis interno ${ }^{88}$

- Formas litúrgico-musicales.

- Cursus: (selección: romano / monástico / no determinable).

- Liturgia:89

- Ciclo litúrgico: (selección: temporal / santoral)

- Solemnidad / fiesta / conmemoración: relacionado con una tabla de festividades.

- Momento litúrgico: (selección: Misa / Oficio Divino / Procesión).

- Dato: oficio determinado, sección de la misa o tipo de procesión.

85 Terminología según Ostos Salcedo, Pardo y Rodríguez 1997.

86 En el campo «Dato» deberá incluirse la propuesta terminológica y el autor que se sigue.

87 Aunque damos por hecho que todos estarán en latín, se deben prever posibles excepciones o la posibilidad de que haya añadidos en lenguas vernáculas, hecho que habría que recoger en la ficha.

${ }^{88}$ En todo este apartado seguimos la terminología del proyecto Cantorales de la BNE, si bien existen otras como las de Asensio Palacios 2003: $262-297$ (oficio divino), $186-240$ (propio de la misa) y $240-263$ (ordinario de la misa).

${ }_{89}$ A pesar de que algunos de los campos de este ítem pueden reiterar cierta información (por ejemplo, el ciclo litúrgico se deduce indirectamente de la solemnidad), hemos preferido dejar todos los campos posibles en la ficha para que el futuro usuario de la base de datos pueda realizar búsquedas a partir de todos ellos. 
- Rúbricas (existencia de los títulos o nombres de las formas litúrgico-musicales que se recogen en el fragmento)..$^{90}$

- Ordines (indicaciones de cómo llevar a cabo la realización, lectura o canto, de las formas litúrgicas que aparecen en el fragmento). ${ }^{91}$

- Transcripción textual.

E. Análisis litúrgico-musical

- Ítems y concordancias textuales de cada ítem (CANTUS Index y otros)..$^{92}$

- Campo de cálculo con el número de concordancias entre diferentes fragmentos.

- Relación de cada ítem del fragmento con otras bases de datos en las que pueda aparecer o en las que haya otras variantes textuales y/o musicales.

- Íncipit musical de cada pieza. ${ }^{93}$

- Campo con otras notas posibles de carácter musicológico.

\section{F. Observaciones}

- Modificaciones: palimpsestos, enmiendas, tachaduras, raspados, espacio para la notación musical y otras roturas.

- Fragmento perdido (en su caso).

- Otras observaciones.

G. Bibliografía

- Recopilación de las referencias bibliográficas existentes en torno al fragmento

La aplicación práctica de esta ficha a un fragmento litúrgico-musical inédito del Archivo Histórico Provincial de Zaragoza se muestra, junto a las imágenes del mismo, en el anexo de este artículo.

\section{A MODO DE CONCLUSIÓN}

El estudio de los fragmentos litúrgico-musicales es una línea de investigación en plena vigencia, tanto fuera como dentro de nuestras fronteras. Hoy día, siguen identificándose, describiendo y analizando documentos de este tipo, ya sean como sujetos pasivos o como objetos activos de un proceso heurístico. La descripción, comparación y análisis de los fragmentos litúrgico-musicales son, como hemos observado, utilizados en varias disciplinas.

Sin embargo, la dispersión de los fragmentos y la diversidad encontrada en los estudios hasta ahora realizados demuestran que es necesaria la creación o, al menos, propuesta de un inventario colectivo o base de datos, tal y como los especialistas en la materia vienen demandando desde hace años.

En España, las publicaciones sobre fragmentos litúrgicomusicales han demostrado ser poco homogéneas en cuanto

90 Calahorra Martínez 2011: 51

91 Ídem.

92 Siempre que sea posible seguiremos a Lacoste et ar. 2012, Kolácek y Helsen (eds.) 2012-. Otras concordancias textuales serán anotadas según convenga, como por ejemplo Deshusses y Darragon (eds.) 1971.

${ }_{93}$ En los casos posibles o en aquéllos cuya reconstrucción sea probable. a extensión, funcionalidad o rigor metodológico, por lo que nuestra propuesta tiene el principal objetivo de contribuir a la unificación de criterios descriptivos al considerar los diversos problemas de catalogación y descripción a los que se enfrenta el investigador de este tipo de documentación, evitando además cualquier complejidad terminológica que fomente la heterogeneidad del resultado.

Por otra parte, el aumento considerable de bases de datos de fuentes primarias de música litúrgica fuera del territorio español, así como la ausencia de cualquier tipo de inventario colectivo dentro de sus fronteras, justifica de algún modo nuestro modelo, el cual, a modo de ejemplo, hemos aplicado a través de la ficha modelo a un fragmento determinado. Esta aplicación ha mostrado ser exhaustiva, útil y tener algunas fortalezas para el potencial uso de terceros. De esta manera, mantiene rigor metodológico y ofrece todos los datos de interés para diversos especialistas, tales como historiadores, filólogos, liturgistas, codicólogos y musicólogos, entre otros.

No obstante, somos conscientes de que la elección de cualquier herramienta, como por ejemplo la ficha que aquí hemos sugerido, se plantea siempre en función del objetivo principal propuesto, el cual es la presentación uniforme de las fuentes primarias basada en un estudio historiográfico de trabajos previos, por lo que consideramos que nuestro texto ha cumplido las expectativas de sus autores, al proponerse esta ficha como punto de inicio y base teórica en la creación de una potencial base de datos.

\section{Anexo. Aplicación de la ficha a un fRAgmento del} ARChivo Histórico Provincial de Zaragoza

RESUMEN DEL ÍTEM: E-Zh Perg. 584, Breviarium, Saturnino, siglo XIV ex. - XV in

A. Identificación

- Siglas RISM/PARES: E-Zh / ES.50297.AHPZ

- Nombre poseedor: Archivo Histórico Provincial de Zaragoza

- Otros nombres por los que se le conoce: AHPZ

- Dirección postal: C/ Diego Dormer 6-8, 50001, Zaragoza

- Tipo de centro: público

- Diócesis: no aplicable

- Persona de contacto archivo/biblioteca: [Directora]

- Signatura: Pergaminos 29-16

B. Imagen

- Signatura digital: Pergamino no 584

- Enlace al objeto digital:

http://dara.aragon.es/opac/app/item/ahpz?vm=nv\&q $=584 \& p=0 \& \mathrm{i}=371509$ [consultado: $10 / 01 / 2016$ ].

- Derechos de acceso y reproducción: [a consultar en archivo $]^{94}$

94 Las imágenes publicadas en este artículo disponen de los permisos necesarios para su reproducción. Agradecemos a la Dra. Maite Iranzo, directora del archivo, su amable gestión. 
C. Análisis externo

- Tipo documento: fragmento

- Tipo de libro: Breviarium

- Datos de la reutilización

- Datación de la reutilización: Cierta: Pleito Civil J13226, año 1778

- Reutilización: cubiertas

- Datos de procedencia o antiguos poseedores: no aplicable

- Anotaciones de archivo: SI.

- Sellos: Ninguno

- Otros fragmentos extraídos del mismo liber tradens: NO

- Del fragmento

- Dimensiones fragmento: 285 x 405 mm.

- Caja escritura:

$\square$ Tipo: dos columnas

$\square$ Dimensiones: 125 x $275 \mathrm{~mm}$.

- Medidas intercolumnio: $12 \mathrm{~mm}$.

- Número de líneas:

$\square$ recto $=1$ a col. 10,5 líneas de texto de $4 \mathrm{~mm}$. / 2a col. 3,5 pautados de $35 \mathrm{~mm}$.

$\square$ vuelto $=2$ cols. de 3,5 pautados de $35 \mathrm{~mm}$.

- Foliación: NO [no visible parte superior]

$\square$ Tipo de foliación: no aplicable

$\square$ Reclamos: NO

- Decoración: 1 inicial quebrada o de cintas y abreviaturas en color rojo

- Datación fragmento: estimada, siglo XIV ex. - Xv in.

- Estado de conservación: fragmento recortado, no restaurado y buen estado

- Posibles copistas o amanuenses: 1 mano para el texto, 2 módulos

- Escritura

- Textual

$\square$ Tipología: gótica libraria, textualis (Canellas 1974).

$\square$ Lengua: latín

$\square$ Módulos empleados: 2, una para texto solo y otra para texto de los cánticos

$\square$ Abreviaturas / Braquiografía: por contracción, suspensión y signos propios

$\square$ Colores: negro (texto) y rojo (rúbricas)

- Musical: con notación

$\square$ Tipología: aquitana, aquitana cuadrada

$\square$ Líneas / pautas: 1 línea a tinta roja

$\square$ Claves: no aplicable

$\square$ Línea de trazo: SI

$\square$ Custos: SI

D. Análisis interno

- Formas litúrgico-musicales: restos de una lectura, un responsorio y tres antífonas

- Cursus: no determinable

- Liturgia:

- Ciclo litúrgico: Santoral

- Solemnidad / fiesta / conmemoración: Saturnino; mártir, obispo de Toulouse, 29-nov

- Momento litúrgico: Oficio Divino

- Dato: Nocturnos de Maitines

- Rúbricas: NO

- Ordines: NO
-Transcripción textual:

- Folio recto

[col. 1] [...] Christianis ipsis propter furorem gentilium sancti viri corpus humare metuentibus, due tantum muliercule sexus infirmitatem fidei virtute vincentes, et viris omnibus forciores, et sui sacerdotis exemplo credo ad tolerantiam passionis amante, benedicti viri corpus ligneo feretro inmersum quam maxime in profundo loco consargo / [col. 2][...] beavit spiritu ut relicto idolorum cultu Deum unium crederent per secula //

- Folio verso

[col. 1] [...] omnibus ad sanctam fidem properantibus copiosa adcrescebat benedictus. p[s]. In Domino confi[do]. a. Quanto amplius Saturnini precibus no / [col. 2] [...] coheres Saturninus electus dei pontifex cuius in habitaculis discordie paratis intraverunt pedes beati perpetuam //

E. Análisis litúrgico-musical

- Recto, col. 1. Lectura: Acta Sanctorum, passio sancti Saturnini ${ }^{95}$

- Recto, col. 2. Responsorio: O quam veneranda immensi (CANTUS ID 601640) ${ }^{96}$

IMAGEN 1

Íncipit de $O$ quam veneranda immensi

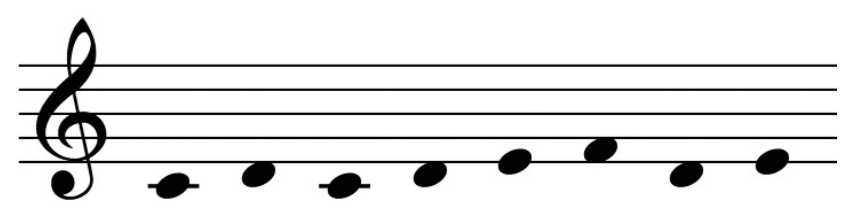

Vuelto, col. 1. Antífona: Opitulantibus autem eximii (CANTUS ID 203695) $^{97}$

IMAGEN 2

Íncipit de Opitulantibus autem eximii

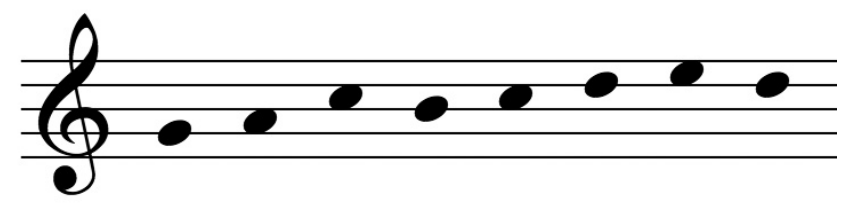

y antífona: Quanto amplius Saturnini (CANTUS ID 204065) ${ }^{98}$

IMAGEN 3

Íncipit de Quanto amplius Saturnini

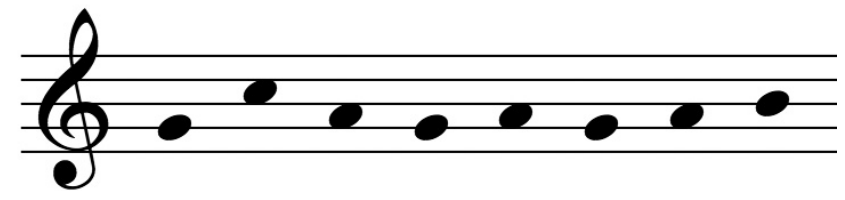

Vuelto, col. 2. Antífona: O quam praefulgida (CANTUS ID 203549) $)^{99}$

95 De la Fuente 1873: 320; y Cabau 2001: 70.

96 E-Tc 44.1, 153r; E-Tc 44.2, 162v; F-Pn lat 1090, 237v.

97 Ibídem, ff. 152r, 162r, 238r respectivamente.

98 ídem.

99 Ídem. 
IMAGEN 4

Íncipit de $O$ quam praefulgida

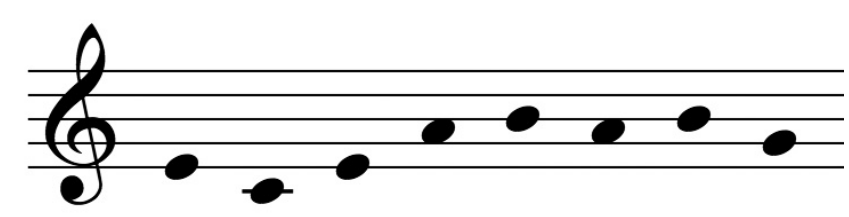

- Campo de cálculo con el número de concordancias: no aplicable

- Relación de cada ítem del fragmento con otras bases de datos en las que pueda aparecer o en las que haya otras variantes textuales y/o musicales: ninguna relación hallada.

- Campo con otras notas posibles de carácter musicológico: el texto de los nocturnos tiene correspondencia con un breviario de uso catedralicio de Toulouse de 1553 impreso en París, el cual es de uso catedralicio. ${ }^{100}$ No obstante, con la información disponible no podríamos asegurar el cursus del códice al que perteneció este fragmento. Sí se aprecia una clara vinculación a las fuentes aquitanas, especialmente con F-Pn lat 1090, antifonario del s. XIII de Marsella.

\section{F. Observaciones}

- Modificaciones: Algunas probatio calami (letras sueltas y un signo) en el recto y vuelto, así como la descripción del censal que encuadernaba: [Censal de 200 sueldos a. [...] del lugar de Alborge, a 15 de marzo. Marzo 12 del 1566. № 2. M. Alborge] La ficha del archivo indica: «cuadernillo con cubiertas de pergamino con notación musical de un censal de 200 sueldos anuales con 4.000 sueldos de propiedad que paga el lugar de Alborge al infanzón Martín del Pin, habitante en Velilla. Hecho en Alborge a 11 de marzo de 1566, ante el notario habitante en Quinto Domingo de Bielsa.»

- Fragmento perdido: no aplicable

- Otras observaciones: sin observaciones

IMAGEN 5

Fragmento AHPZ, perg. 584, recto

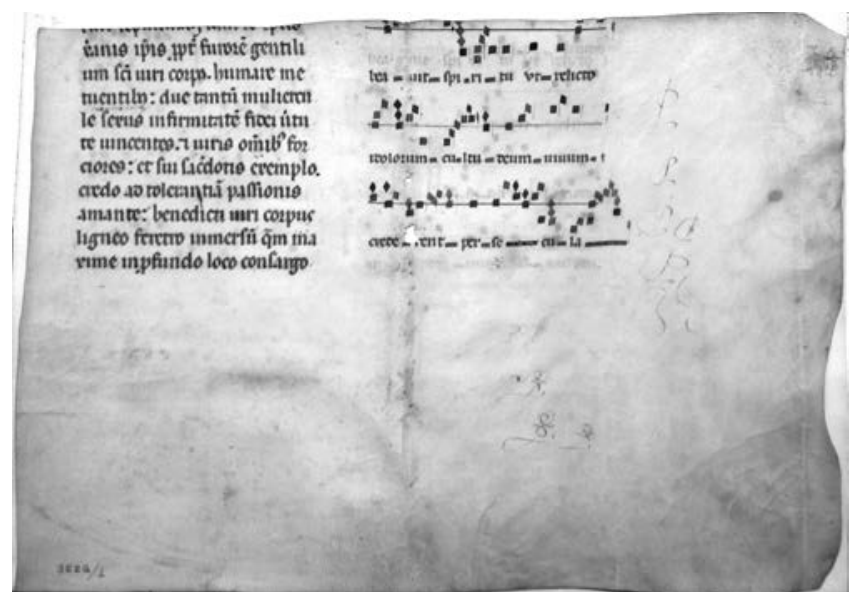

100 Office ancien de Saint Saturnin (nํ), en Latou 1864: 293.
IMAGEN 6

Fragmento AHPZ, perg. 584, vuelto

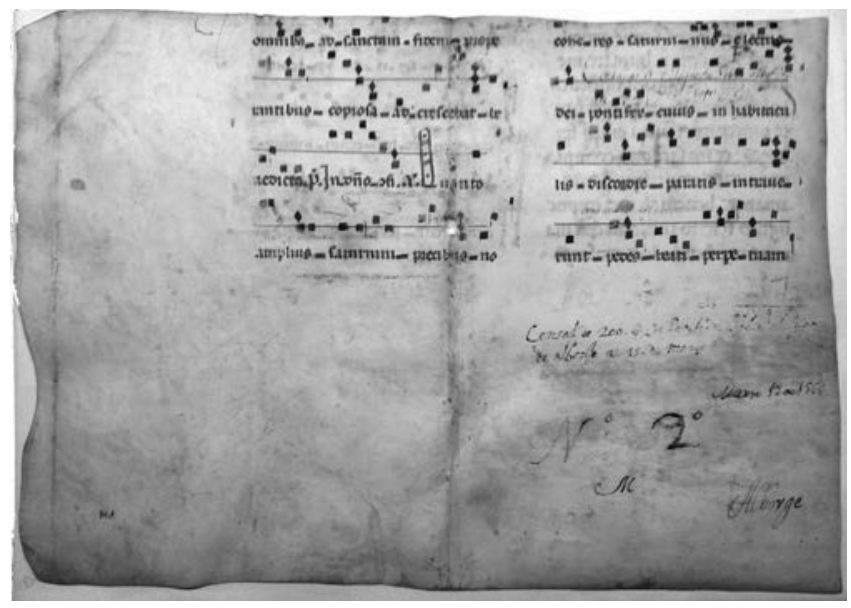

\section{BiBLIOgRAFÍA CITADA}

Alturo Perucho, J. 1990. "Los estudios sobre fragmentos y Membra Disiecta de códices en Cataluña: breve estado de la cuestión», en J.M. Martí Bonet y M. Vicario Santamaría (eds.), Los archivos de la Iglesia, presente y futuro: 33-52 [s.I.]: Akribos.

Alturo Perucho, J. 1999. Studia in codicum fragmenta. Bellaterra: Universitat Autònoma de Barcelona.

Álvarez Márquez, M. C. 1985. «Escritura latina en la Plena Edad Media: la llamada "gótica libraria» en España» Historia, Instituciones, Documentos 12: 377-410.

Andrés Fernández, D. 2013. "Los fragmentos litúrgico-musicales del Archivo Histórico Provincial de Zaragoza (siglos XII-XVI) (1a parte)», Nassarre: revista aragonesa de musicología 29: 209-246.

Anglés, H. 1935. La música a Catalunya fins al segle XIII. Barcelona: Institut d'Estudis Catalans.

Asensio Palacios, J. C. 2003. El canto gregoriano: historia, liturgia, formas. Madrid: Alianza Música.

Baroffio, B. 1990. "I manoscritti liturgici», en V. Jemolo y M. Morelli (eds.), Guida a una descrizione uniforme dei manoscritti e a loro censimento: 143-192. Roma: ICCU.

Baroffio, B. 1995-1996. "I frammenti liturgici», Rassegna degli Archivi di Stato 55: 334-355.

Berenbeim, J. 2010. "Script After Print: Juan de Yciar and the Art of Writing», Word \& Image 26/3: 231-243.

Bergeron, K. 1998. Decadent enchantments: the revival of Gregorian chant at Solesmes. Berkeley - London: University of California Press.

Bernardo de Quirós, L. (coord.). 2003. Informe de catalogación de manuscritos, 2003 http://www.mcu.es/bibliotecas/docs/Informe_ Catalogacion_de_manuscritos2003.pdf.

Bohigas, P., Mundó, A. y Soberanas, A. J. 1973-1974. «Normes per a la descripció codicológica dels manuscrits», Biblioteconomia 30-31/77-78: 93-100.

Brou, L. 1950. "Les fragments wisigothiques de I'Université de Cambridge», Hispania Sacra 3: 139-144.

Brunius, J. 2002. "Scanning of Medieval Book Fragment in the Swedish National Archives», en Riksbankens Jubileumsfond, http://anslag. rj.se/en/fund/29251 [consultado: 10/01/2016].

Burón Castro, T. 1973. «Fragmentos de códices visigóticos en el Archivo Histórico Provincial de León», Archivos Leoneses: revista de estudios y documentación de los Reinos Hispano-Occidentales 53: 9-55.

Burón Castro, T. 1978. «Fragmentos de códices visigóticos en el Archivo Histórico de León, I. Astorga», Archivos Leoneses: Revista de estudios y documentación de los Reinos Hispano-Occidentales 63: 137-164. 
Burón Castro, T. 1979. «Fragmentos de códices visigóticos en el Archivo Histórico Provincial de León: II. Villafranca del Bierzo», Archivos Leoneses: revista de estudios y documentación de los Reinos Hispano-Occidentales 65: 75-102.

Burón Castro, T. 1980. «Fragmentos de códices visigóticos en el Archivo Histórico Provincial de León: III, Ponferrada», Archivos Leoneses: revista de estudios y documentación de los Reinos HispanoOccidentales 67: 117-136.

Burón Castro, T. 1981. «Fragmentos de códices visigóticos en el Archivo Histórico Provincial de León: IV, Sahagún», Archivos Leoneses: revista de estudios y documentación de los Reinos HispanoOccidentales 69: 169-176.

Burón Castro, T. 1985. «Fragmento visigótico de la «Passio Fructuosi, auguri et eulogii», Archivos Leoneses: revista de estudios y documentación de los Reinos Hispano-Occidentales 78: 373-374.

Burón Castro, T. 1987. "Colligite fragmenta...», Boletín Anabad xxxvii/3: 289-392.

Burón Castro, T. 1992. «Aportación de fuentes para el estudio del Canto Llano. Fragmentos musicales del Archivo Histórico Provincial de León», en Á. Galindo García (ed.), La música en la Iglesia: de ayer y hoy: 287-301. Salamanca: Universidad Pontificia de Salamanca.

Burón Castro, T. 1995a. «Pergaminos impresos inventariados en el Archivo Histórico Provincial de León», Revista Estudios Humanísticos, Geografía, Historia y Arte 17: 95-120.

Burón Castro, T. 1995b. «Recursos y posibilidades de los fragmentos en archivos y bibliotecas», en A. Hevia Ballina (ed.), Memoria Ecclesiae VI y VII. Órdenes monásticas y archivos de la Iglesia II: santoral hispanomozárabe en España: 507-514. Oviedo: Asociación de Archiveros de la Iglesia en España.

Burón Castro, T. 1997. "Pergaminos impresos inventariados en el Archivo Histórico Provincial de León», Estudios humanísticos. Geografía, historia y arte 17: 95-120.

Burón Castro, T. 2000. «Fragmentos de códices litúrgicos conservados en el Archivo Histórico Provincial de León», León y su historia: miscelánea histórica, VI: 149-477. León: Centro de Estudios e Investigación San Isidoro - Archivo Diocesano de León - Caja España de Inversiones.

Burón Castro, T. 2002. Manual para la recuperación de fragmentos de manuscritos, impresos y otros documentos especiales en archivos y bibliotecas. León: T. Burón.

Cabau, P. 2001. «Opusculum de passione ac translatione sancti Saturnini, episcopi Tolosanae ciuitatis et martyris (édition et traduction provisoires)", Mémories de la Société Archéologique du Midi de la France 61: 59-77.

Cabero Pueyo, B. 1992. «El fragmento con polifonía litúrgica del s. xv E-Ahl 1474/17. Estudio comparativo sobre el Kyrie Summa Clementissime», Anuario musical 47: 39-80.

Calahorra Martínez, P. 2004. «De los pergaminos sueltos, fragmentos -iAy dolor!- de valiosos códices medievales», en P. Calahorra Martínez y L. Prensa Villegas (eds.), VIII Jornadas de Canto Gregoriano. Canto Gregoriano en Aragón: de códices e iglesias medievales, y de los hombre que los vivificaron y las habitaron: 97-117. Zaragoza: Institución Fernando el Católico.

Calahorra Martínez, P. 2011. Fragmentos litúrgico-musicales (ss. XIIIXVI) del Archivo Histórico Notarial de Daroca (Zaragoza). Zaragoza, Institución Fernando el Católico.

Canellas López, A. 1974. Exempla scripturarum latinarum, 2 vols. Zaragoza, Libreria General.

Castillo Pérez, C. y Romero Andonegi, A. 2008. «Propuesta de adaptación de la norma ISAD(G) en un caso concreto: la colección facticia de pergaminos litúrgicomusicales del Archivo Histórico Eclesiástico de Vizcaya», en A. Hevia Bellina (ed.), Memoria Ecclesiae XXXI. Música y archivos de la iglesia. Santoral hispano-mozárabe en las diócesis de España: 713-723. Oviedo: Asociación de Archiveros de la Iglesia en España.

Conde López, R. M. 1997. «La supervivencia de los códices litúrgico musicales en la Baja Edad Media: causas y legislación», Edades 1: 139-145.

Conde López, R. M. 1998. Catálogo de manuscritos musicales de Cantabria: siglos XIII al XVI. Santander: Ayuntamiento de Santander.
De la Fuente, V. 1873. Historia Eclesiástica de España, Tomo I. Madrid: Impresores y libreros del Reino.

Deshusses, J. y Darragon, B. (eds.) 1971. Concordances et tableaux pour l'étude des grands sacramentarium. Fribourg: Editions Universitaries Fribourg.

Derolez, A. 2003. The palaeography of Gothic manuscript books: from the twelfth to early sixteenth century. Cambridge: Cambridge University Press.

Díaz y Díaz, M. 1992. "Códices y fragmentos de códices», en A. Hevia Ballina (ed.), Iglesia y cultura en las edades media y moderna: santoral hispano-mozárabe en España: 41-44. [s.l.]: Asociación de Archiveros de la Iglesia en España.

Ellis, K. 2013. The politics of plainchant in fin-de-siècle France. Farnham: Ashgate.

Extremiana Navarro, P. 2002. Monodía litúrgica en La Rioja: Catedral de Calahorra, Santo Domingo de La Calzada y Seminario Diocesano de Logroño (siglos XII-XIX). Logroño: Universidad de La Rioja.

Extremiana Navarro, P. y Camacho Sánchez, P. 2004. "Análisis y estudio de fragmentos musicales de monodía litúrgica en La Rioja», Kalakorikos: Revista para el estudio, defensa, protección y divulgación del patrimonio histórico, artístico y cultural de Calahorra y su entorno 9: 59-82

Fassler, M. 2010. "Cataloguing Medieval Manuscript Fragments: A Window on the Scholar's Workshop, with an Emphasis on Electronic Resources», en E.G. Heller y P.C. Pongracz (eds.), Perspectives on medieval art. Learning through looking: 109-125. New York: Museum of Biblical Art.

Fernández de la Cuesta, I. 1980. Manuscritos y fuentes musicales en España: Edad Media. [Madrid]: Alpuerto.

Fernández de la Cuesta, I. 1991. «La restauración del canto gregoriano en la España del siglo XIX», Revista de musicología 14: 481-488.

Fernández de la Cuesta, I. y Del Álamo, C. 1979. "Fragmento de un Salterio visigótico con notación musical», Revista de musicología 2/1: 9-18.

Fonseca Ruiz, I. (ed.) 1999. Reglas de catalogación españolas. Madrid: Ministerio de Educación y Cultura, Centro de Publicaciones.

García Fraile, D. 1981. Catálogo Archivo de música de la Catedral de Salamanca. Cuenca: Instituto de Música Religiosa de la Diputación Provincial.

Garrigosa Massana, J. 1994. Catálogo de manuscritos e impresos musicales del Archivo Histórico Nacional y del Archivo de la Corona de Aragón. Madrid: Dirección General de Bellas Artes y Archivos.

Gómez Muntané, M. C. 1985. «Un nuevo manuscrito con polifonía antigua en el Archivo Diocesano de Solsona», Recerca musicològica 5: 5-11.

Gómez Muntané, M. C. 1989-1990. «El manuscrito 1bis del Monasterio de Santa Maria de Vallbona», Recerca musicològica 9-10: 59-72.

Gros Pujol, M. 1977. «El fragment del «Liber Psalmorum» hispànic. Vic, Mus. Epis., MS. 259», Revista Catalana de Teologia 2: 437-452.

Gros Pujol, M. 1995. "Els Fragments del sacramentari Vic, Museu Episcopal, Frag. 1/8», Miscel-lània litúrgica catalana 6: 165-175.

Gros Pujol, M. 1998. «Els fragments del «Liber Misticus» de la canònica de Santa Maria de Manlleu», Analecta sacra Tarraconensia: Revista de ciènces historicoeclesiàstiques 71: 343-357

Gros Pujol, M. 2008. «El fragment de sacramentari gironí, Barcelona, Bib. Univ., Ms. 1949/16», Annals de l'Institut d'Estudis Gironins 49: 197-204.

Gros Pujol, M. 2009. «Fragments d'un antifonari de l'ofici diví de Besiers (Tarragona, Arx. Hist. Arxid., Frag. 19/1)», Miscel-lània Litúrgica Catalana 17: 47-81.

Gros Pujol, M. 2013. «Fragments d'un antic breviari coral d'un monestir català», Studia monastica 55/1: 27-41.

Guéranger, P. 1840-1841. Institutions liturgiques, 2 vols. Mans - Paris: Fleuriot - Débécourt.

Gutiérrez González, C. J. y Lara Lara, F. J. 1992. «Fragmentos de música medieval en Astorga. Catalogación de fragmentos y hojas de guarda de manuscritos litúrgico-musicales del archivo diocesano», Archivos Leoneses: revista de estudios y documentación de los Reinos Hispano-Occidentales 91-92: 399-423. 
Hevia Ballina, A. (ed.) 2008. Memoria Ecclesiae XXXI: Música y archivos de la iglesia. Santoral hispano-mozárabe en las diócesis de España. Oviedo: Asociación de Archiveros de la Iglesia en España.

Huglo, M. 1980. Les livres de chant liturgique. Turnhout: Brepols.

Hughes, A. 1995. Medieval manuscripts for mass and office: a guide to their organization and terminology. Toronto: University of Toronto Press.

Ibarz Ferré, M. T. 1997. «El canto gregoriano en Zaragoza. Fragmentos con notación musical de los siglos XII al XVII», Revista de musicología 20/2: 1101-1104.

Ibarz Ferré, M. T. 1998. Programa de investigación "Fragmentos I»: primeras conclusiones: catalogación y estudio de las fuentes musicales que se conservan en los protocolos notariales aragoneses. Barcelona: ETD Micropublicaciones.

Janini Cuesta, J. 1965. «Los fragmentos de Sacramentarios existentes en Vich», Hispania sacra 18/36: 385-409.

Janini Cuesta, J. 1966. «Los fragmentos visigóticos de San Zoilo de Carrión», Liturgica 3: 73-83.

Janini Cuesta, J. 1968. "Un fragmento visigótico de «Manuale» toledano", Hispania Sacra 21: 379-389.

Janini Cuesta, J. 1975. "La colección de fragmentos litúrgicos de Vic», Analecta sacra tarraconensia: Revista de ciències historicoeclesiàstiques 48: 3-32.

Janini Cuesta, J. 1976a. «Dos fragmentos del «Liber Ordinum», Studia Silensia 3: 227-231.

Janini Cuesta, J. 1976b. «Los fragmentos litúrgicos del Archivo Histórico Nacional, de Madrid (Sección de Códices, 1453 B-1486 B)», Revista de archivos, bibliotecas y museos LXXIX/1: 43-72.

Janini Cuesta, J. 1977. Manuscritos litúrgicos de las bibliotecas de España: I Castilla y Navarra. Burgos: Aldecoa.

Janini Cuesta, J. 1978. "Fragmentos litúrgicos de Cataluña», Miscel/lània litúrgica catalana 1: 69-88.

Janini Cuesta, J. 1980. Manuscritos litúrgicos de las bibliotecas de España: Il Aragón, Cataluña y Valencia. Burgos: Aldecoa.

Janini Cuesta, J. y Ricoma, J. 1965. «Fragmentos litúrgicos del Archivo Archidiocesano de Tarragona», Analecta sacra tarraconensia: Revista de ciències historicoeclesiàstiques 38: 217-230.

Lacoste, D., Kolácek, J. y Helsen, K.E. (eds.) 2012-. CANTUS Index: Online catalogue for Mass and Office chants. Catalogue of Chant Texts and Melodies. University of Waterloo, http://cantusindex. org/

Latou, M. 1864. Vie de Saint Saturnin. Toulouse: Lib. Léopold Cluzon.

Lieftinck, G.I. 1953. "Pour une nomenclature de l'ècriture livresque de la période dite gothique», en Nomenclature des écritures livresques du I $X^{e}$ au XVI siècle: 15-34, Paris.

Martí Martínez, C. 2013. Manuscritos litúrgico-musicales reutilizados en España. Tesis de Fin de Máster. Madrid, Universidad Complutense de Madrid.

Martín Fuertes, M. 1987. «Un fragmento de breviario del siglo XII», en Santo Martino de León. Ponencias del I Congreso Internacional sobre Santo Martino en el VIII Centenario de su obra literaria, 1185-1985. León: Isidoriana: 279-296.

Medina Álvarez, A. 1994. Pergaminos litúrgico musicales del archivo municipal del Ayuntamiento de Oviedo. Oviedo: Ayuntamiento de Oviedo.

Medina Álvarez, A. 1995. "Los libros de coro del Monasterio de Santa María de Valdedios: estudio y catalogación», en A. Hevia Ballina (ed.), Memoria Ecclesiae VI y VII. Órdenes monásticas y archivos de la Iglesia II: santoral hispano-mozárabe en España: 207-234. Oviedo: Asociación de Archiveros de la Iglesia en España.

Montero García, J. (ed.) 2011. Catálogo de Fondos Musicales del archivo Catedral de Salamanca. Salamanca: Catedral de Salamanca.

Mundó, A. M. 1982. «Méthode comparative-statistique pour la datation des manuscrits non datés», en Paläographie 1981: Colloquium des Comité International de Paléographie» (Munich, septiembre de 1981): 53-58. München: Arbeo-Geselischaft.

Muzerelle, D. 1985. Vocabulaire codicologique : répertoire méthodique des termes français relatifs aux manuscrits. Paris: Editions CEMI.
Nelson, K. E. 1993. "A fragment of medieval polyphony in the Archivo Histórico Provincial of Zamora», Plainsong \& Medieval Music 2/2: 141-152.

Nuñez Fernández, E. 1995. «Fragmentos de antifonarios y cantorales litúrgicos del Archivo Municipal de Gijón», en A. Hevia Ballina (ed.) Memoria Ecclesiae VI y VII. Órdenes monásticas y archivos de la Iglesia II: santoral hispano-mozárabe en España: 493-497. Oviedo: Asociación de Archiveros de la Iglesia en España.

Ostos Salcedo, P., Pardo, M. L. y Rodríguez, E. E. 1997. Vocabulario de codicología. Versión española revisada y aumentada. Madrid: Arco Libros.

Palazzo, E. 1993. Histoire des livres liturgiques: Le Moyen Age, des origines au XIII siècle. Paris: Beauchesne.

Palazzo, E. 1998. A history of liturgical books: from the beginning to the thirteenth century. Collegeville: The Liturgical Press.

Pellegrin, E. 1980. «Fragments et membra disiecta», en J. P. Gumbert, J. M. De Haan y A. Gruys (eds.), Codicologica, 3. Essais typologiques: 70-95. Leiden: Brill.

Peñas García, M.C. 2004. Fondos musicales históricos de Navarra. Siglos XII-XVI. Pamplona: Universidad Pública de Navarra.

Perani, M. y Ruini, C. (eds.) 2002. "Fragmenta ne pereant»: recupero e studio dei frammenti di manoscritti medievali e rinascimentali riutilizzati in legature. Ravenna: Longo.

Prensa Villegas, L. 2000. «Recuperación del repertorio gregoriano en Aragón, a través de los fragmentos de códices litúrgicos, utilizados como tapas de protocolos notariales», Aragón en la Edad Media 16: 659-682.

Prensa Villegas, L. 2004. «El códice: un mundo de sabiduría en manos del copista», en L. Prensa Villegas y P. Calahorra Martínez (eds.), Actas VIII Jornadas de Canto Gregoriano (Zaragoza, noviembre de 2003): 11-34. Zaragoza: Institución Fernando el Católico.

Prensa Villegas, L. 2010. «Fragmentos litúrgico-musicales (ss. XIII-XVI) en el Archivo Histórico Notarial de Daroca», Nassarre: revista aragonesa de musicología 26: 179-240.

Rey Olleros, M. 2007. La música medieval en Ourense. I. Pergaminos del Archivo Histórico Provincial. Orense: Armonia Universal.

Rey Olleros, M. 2008. La música medieval en Ourense. II. Pergaminos del Archivo Histórico Diocesano. Orense: Armonia Universal.

Rey Olleros, M. 2009. La música medieval en Ourense. III. Pergaminos del Archivo Capitular. Orense: Armonia Universal.

Rey Olleros, M. 2013a. La música medieval en Compostela. Pergaminos del Archivo de la Catedral. Orense: Armonia Universal.

Rey Olleros, M. 2013b. La música medieval en Pontevedra. I. Pergaminos del Archivo Histórico Provincial. Orense: Armonia Universal.

Rey Olleros, M. 2013c. La música medieval en Pontevedra. II. Pergaminos del Archivo Capitular de Tui. Orense: Armonia Universal.

Rodríguez Suso, C. 1993a. Fragmentos con notación musical en el País Vasco (siglos XIII-XVIII). Bilbao: Universidad de Deusto.

Rodríguez Suso, C. 1993b. La monodia litúrgica en el País Vasco: Fragmentos con notación musical de los siglos XII al XVIII, 3 vols. Bilbao: Bilbao Vizkaia Kutxa.

Ruiz García, E. 1988. Manual de Codicología. Madrid: Fundación Germán Sánchez Ruipérez.

Ruiz Torres, S. 2010. «El rito romano en la Segovia medieval: catalogación y análisis de unos fragmentos litúrgicos (siglos XII-XVI)», Hispania Sacra 62(126): 407-455.

Ruiz Torres, S. 2016. «Los fragmentos litúrgicos del Archivo Capitular de Huesca (siglos XI-XVI)», Miscel·lània Litúrgica Catalana 24: 79-120.

Sánchez Mairena, A. 2015. «Selección bibliográfica de investigaciones sobre manuscritos litúrgicos en España», Memoria Ecclesiae 39: 617-683.

Sánchez Mairena, A. y Pelayo Piqueras, J. A. 2015. «Noticia de fragmento litúrgico medieval en el Archivo Municipal de Loja (Granada)», Memoria Ecclesiae 39: 309-324.

Tedeschi, M.G. 1990. "I manoscritti musicali», en V. Jemolo y M. Morelli (eds.), Guida a una descrizione uniforme dei manoscritti e a loro censimento: 103-142. Roma: ICCU. 
Varona García, M. A. 1973. «Fragmento de un Salterio visigótico en e Archivo de la Real Chancillería de Valladolid», Hispania Sacra 26 239-246.

Zapke, S. 2007a. Fragmentos litúrgico-musicales de la Edad Media en archivos de Aragón (siglos XI ex. - XIV ex.): catalogus codicum mutilorum aragoniensis. Huesca - Zaragoza: Instituto de Estudios Altoaragoneses - Departamento de Educación, Cultura y Deporte del Gobierno de Aragón.
Zapke, S. (ed.) 2007b. Hispania Vetus: manuscritos litúrgico-musicales: de los orígenes visigóticos a la transición francorromana (siglos IXXII). Bilbao: Fundación BBVA.

Zapke, S. 2007c. «Sistemas de notación en la Península Ibérica: de las notaciones hispanas a la notación aquitana (siglos IX-XII)», en S. Zapke (ed.), Hispania Vetus: manuscritos litúrgico-musicales: de los orígenes visigóticos a la transición francorromana (siglos IXXII): 189-243. Bilbao: Fundación BBVA. 